\title{
Preparation and Characterization of High-Efficiency Magnetic Heavy Metal Capture Flocculants
}

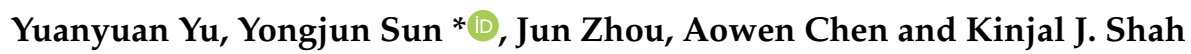 \\ College of Urban Construction, Nanjing Tech University, Nanjing 211800, China; justina20212021@163.com (Y.Y.); \\ xuefengnjut@163.com (J.Z.); Chenaowen2021@163.com (A.C.); kjshah@njtech.edu.cn (K.J.S.) \\ * Correspondence: sunyongjun@njtech.edu.cn
}

Citation: Yu, Y.; Sun, Y.; Zhou, J.;

Chen, A.; Shah, K.J. Preparation and Characterization of High-Efficiency Magnetic Heavy Metal Capture Flocculants. Water 2021, 13, 1732. https://doi.org/10.3390/w13131732

Academic Editor: Margaritis Kostoglou

Received: 14 May 2021

Accepted: 20 June 2021

Published: 23 June 2021

Publisher's Note: MDPI stays neutral with regard to jurisdictional claims in published maps and institutional affiliations.

\begin{abstract}
In this study, a high-efficiency magnetic heavy metal flocculant MF@AA was prepared based on carboxymethyl chitosan and magnetic $\mathrm{Fe}_{3} \mathrm{O}_{4}$. It was characterized by SEM, FTIR, XPS, XRD and VSM, and the $\mathrm{Cu}(\mathrm{II})$ removal rate was used as the evaluation basis for the preparation process. The effects of AMPS content, total monomer concentration, photoinitiator concentration and reaction time on the performance of MF@AA flocculation to remove $\mathrm{Cu}(\mathrm{II})$ were studied. The characterization results show that MF@AA has been successfully prepared and exhibits good magnetic induction characteristics. The synthesis results show that under the conditions of $10 \%$ AMPS content, $35 \%$ total monomer concentration, $0.04 \%$ photoinitiator concentration, and $1.5 \mathrm{~h}$ reaction time, the best yield of MF@AA is $77.69 \%$. The best removal rate is $87.65 \%$. In addition, the response surface optimization of the synthesis process of MF@AA was performed. The optimal synthesis ratio was finally determined as iron content $6.5 \%$, CMFS: $29.5 \%$, AM: $53.9 \%$, AMPS: $10.1 \%$. High-efficiency magnetic heavy metal flocculant MF@AA shows excellent flocculation performance in removing $\mathrm{Cu}$ (II). This research provides guidance and ideas for the development of efficient and low-cost flocculation technology to remove $\mathrm{Cu}(\mathrm{II})$ in wastewater.
\end{abstract}

Keywords: magnetic flocculation; heavy metal; response surface method; model optimization

\section{Introduction}

Water sources are severely polluted by heavy metal ions and organic compounds produced daily by industrial, agricultural, transportation, and residential activities [1]. Specifically, heavy metal ions in wastewater produced by industrial activities such as metal smelting, electrolysis, and electroplating cannot be degraded by microorganisms, resulting in soil, water, and air pollution [2]. In addition, due to the non-degradability, bioaccumulation and toxicity of heavy metals (such as lead, cadmium, mercury, chromium, copper, zinc, nickel, etc.), it is essential to solve the problem relating to heavy metal pollution to achieve global sustainability [3]. Among all the listed heavy metal pollutants, copper in the water enters the human body through the food chain, which will have a subtle impact on human health, such as liver failure, headache, hypoglycemia, and nervous system poisoning, so it is necessary to remove copper ions in wastewater [4]. In that regard, many countries have set stringent limits on emissions, and the critical goal is to make the emissions of heavy metals close to zero [5]. Thus, there is an urgent need to develop a cost-effective water treatment method.

At present, plenty of technologies for removing heavy metals in wastewater have been successfully developed, such as adsorption, photocatalysis, precipitation, coagulation, and flocculation [6]. Among them, flocculation is a convenient, economic and efficient wastewater treatment technology. It has been widely used as the basic operation unit of conventional water treatment [7]. The selection of flocculants has a significant influence on the flocculation process. There is no doubt that the development of economical, efficient, and environmentally friendly flocculants is the utmost priority [8]. In the past few decades, 
inorganic and organic polymer flocculants have shown surprising efficiency during the flocculation process. However, some of them often cause new environmental challenges and produce secondary pollution to the environment, including residual metal ions produced by inorganic flocculants, the problem of toxic monomer residues in synthetic organic polymer flocculants, etc. [9]. Therefore, compared with traditional flocculants, natural organic polymers and their modified flocculants have become an area of interest for researchers due to their high efficiency, low cost, and biodegradability. As a natural polymer material, chitosan is a cationic polyelectrolyte, which has been used in many fields due to the protonation of its amino group [10]. However, due to its limitation with solubility only in acidic solutions, its application in the preparation of flocculants is limited. This obtained behavior is due to strong intermolecular and intramolecular hydrogen bonds in chitosan. It can only be dissolved in acidic solutions [11]. In other words, under such acidic conditions, chitosan is partially degraded, resulting in a significantly reduced molecular weight, and the flocculation efficiency may also be reduced [12]. Therefore, it is necessary to overcome these shortcomings through chemical modification and improve its flocculation performance. In general, carboxymethyl was introduced into chitosan to prepare modified carboxymethyl chitosan (CMFS), which contains $-\mathrm{COOH},-\mathrm{NH}_{2},-\mathrm{OH}$ and other groups to enhance chemical capabilities [13].

Recently, magnetic flocculation is an emerging technology widely used in solid-liquid separation in water treatment under an external magnetic field. It has the advantages of effective capture, rapid settlement, easy recovery and recyclability [14]. In addition, the flocs produced by magnetic flocculation will not be broken and dispersed into the water due to the strong magnetic attraction between the flocs and the external magnet. Thus it will solve the problem of the resuspension of the flocs [15]. Furthermore, CMFS can be modified by graft copolymerization to further improve the flocculation performance of CMFS. The modification aims to increase the charge density and molecular weight and further improve the solubility. In addition, the graft copolymerization of CMFS and a cationic monomer combines the advantages of cationic, anionic and other functional groups [16]. These groups can significantly increase the charge density and adsorption bridging ability [17]. As a result, the length of the molecular chain increases, and the scope of application is gradually expanded.

In this study, carboxymethyl chitosan and magnetic $\mathrm{Fe}_{3} \mathrm{O}_{4}$ were used as substrates, and the high-efficiency magnetic heavy metal flocculant (MF) MF@AA was synthesized by UV-initiated copolymerization technology. The structure was characterized by using a scanning electron microscope (SEM), infrared spectrometer (FTIR), X-ray diffraction (XRD), $\mathrm{X}$-ray photoelectron spectrometer (XPS) and vibrating sample magnetometer (VSM). The factors such as the influence of AMPS content, total monomer concentration, photoinitiator concentration and reaction time on the preparation of MF@AA were investigated through single-factor experiments, and the optimal preparation conditions were determined. In addition, the optimal synthesis conditions were obtained by response surface optimization of the distribution ratio of MF@AA prepared by the Central Composite model.

\section{Materials and Methods}

\subsection{Materials}

Carboxymethyl chitosan (CMFS), azodiisobutamidine hydrochloride (V-50), acrylamide (AM), 2-acrylamide-2-methyl-propane-sulfonic acid (AMPS) and azobis-isobutamidine phosphate are all analytically pure, purchased from Shanghai Aladdin Biochemical Technology Co., Ltd. (China). Ferrous sulfate $\left(\mathrm{FeSO}_{4} \cdot 7 \mathrm{H}_{2} \mathrm{O}\right)$, ferric sulphate $\left(\mathrm{Fe}_{2}\left(\mathrm{SO}_{4}\right)_{3} \cdot 9 \mathrm{H}_{2} \mathrm{O}\right)$, absolute ethanol $\left(\mathrm{C}_{2} \mathrm{H}_{5} \mathrm{OH}\right)$, and concentrated sulfuric acid $\left(\mathrm{H}_{2} \mathrm{SO}_{4}\right)$ are all analytically pure and were purchased from Sinopharm Chemical Reagent Co., Ltd. (China). Sodium hydroxide $(\mathrm{NaOH})$ is of analytical grade and was purchased from Nanjing Chemical Reagent Co., Ltd. (China). Copper chloride $\left(\mathrm{CuCl}_{2} \cdot 2 \mathrm{H}_{2} \mathrm{O}\right)$ is analytically pure and was purchased from Nanjing Shengjian Quanhua Glass Instrument Co., Ltd. (China). High purity nitrogen $\left(\mathrm{N}_{2}\right)$ was purchased from Nanjing Sanle Electronic Information Industry Group Co., Ltd. 
(China). All these chemical reagents were used in the experiment, are of analytical grade and can be used without further purification. All solutions used in experiments were prepared with deionized water.

\subsection{Preparation Method of $M F @ A A$}

Preparation scheme of MF@AA is shown in Figure S1. $\mathrm{Fe}_{3} \mathrm{O}_{4}$ was prepared by coprecipitation method. A total of $4.84 \mathrm{~g} \mathrm{FeSO} \cdot 5 \mathrm{H}_{2} \mathrm{O}$ and $8.36 \mathrm{~g} \cdot \mathrm{Fe}_{2}\left(\mathrm{SO}_{4}\right)_{3} 9 \mathrm{H}_{2} \mathrm{O}$ were weighed into a $500 \mathrm{~mL}$ three-necked flask with adding $160 \mathrm{~mL}$ deionized water. The mixed solution was ultrasonically reacted for $30 \mathrm{~min}$ and stirred at a constant speed. Then, the wide-mouthed quartz bottle was placed at a water bath to maintain a constant $80{ }^{\circ} \mathrm{C}$ temperature until obtaining a complete dissolution. After dissolution, $1.0 \mathrm{~mol} / \mathrm{L} \mathrm{NaOH}$ solution was slowly added to the mixture drop-wise to maintain the $\mathrm{pH}$ at about 10 . Once the basic $\mathrm{pH}$ was obtained, around about $10 \mathrm{~min}$, carboxymethyl chitosan was added and stirred well until it was completely dissolved. In order to avoid oxidation, nitrogen gas was purged into the quartz bottle for $30 \mathrm{~min}$ to remove oxygen. The photoinitiator (V-50) was added, and then nitrogen gas was purged again for 5 min and then the quartz bottle was sealed. This quartz bottle was irradiated with ultraviolet light. The product was taken out after polymerization for $2 \mathrm{~h}$, and cured for 1.0-1.5 h, and the colorless translucent gel obtained was called MF. Finally, it was purified with ethanol, dried in an oven at $60{ }^{\circ} \mathrm{C}$ for $4 \mathrm{~h}$, and then ground through a 50-mesh sieve to obtain MF powder samples. To synthesize magnetic heavy metal flocculant (MF@AA), MF, AM and AMPS were put into a wide-mouthed quartz bottle according to the mass ratio (iron component $6.5 \%$, CMFS $29.5 \%$, AM 53.9\%, AMPS 10.1\%) determined by the experimental design. Then, MF preparation method was repeated to obtain the MF@AA product. MFM is prepared by MF and AM similar to the preparation method of MF@AA. The percentage of the total mass of the synthesized product to the total mass of the monomer used is taken as the productivity index.

\subsection{Characterization Method of MF@AA}

The surface morphology, distinct groups and crystal morphology of the prepared magnetic carboxymethyl chitosan-based flocculant were characterized by FTIR, SEM, XRD, XPS and VSM analytical techniques. FTIR (IFS 66/S, Bruker, Karlsruhe, Switzerland) obtained the infrared spectrum of the magnetic carboxymethyl chitosan-based flocculant through the potassium bromide method. The apparent morphology of the magnetic carboxymethyl chitosan-based flocculant was observed with an SEM (TM3000, Hitachi, Tokyo, Japan). The XRD pattern of the magnetic carboxymethyl chitosan-based flocculant was obtained with an X-ray diffractometer (Rigako Industrial Co., Ltd., Aichi Prefecture, Toyota City, Japan). The X-ray photoelectron spectroscopy of the magnetic carboxymethyl chitosan-based flocculant was obtained with XPS (Amicus, Shimadzu, Tokyo, Japan). A vibrating sample magnetometer (Model 7404, LakeShore Corporation, Columbus, OH, USA) obtained the magnetic carboxymethyl chitosan-based flocculant's magnetic properties.

\subsection{Coagulation Experiments}

A $100 \mathrm{mg} / \mathrm{L} \mathrm{Cu}(\mathrm{II})$ solution was prepared with copper chloride, and the required $\mathrm{pH}$ value was adjusted with $0.1 \mathrm{~mol} / \mathrm{L} \mathrm{NaOH}$ and $\mathrm{H}_{2} \mathrm{SO}_{4}$ solution. The $\mathrm{G}$ value was controlled by adjusting the speed. Before the start of the coagulation experiment, the flocculants were added. After the coagulation, $400 \mathrm{~mL}$ of turbid liquid was taken in a beaker and placed under a magnetic field for 15 min precipitation. After precipitation, the supernatant at $2 \mathrm{~cm}$ of the liquid surface was aspirated to determine the concentration of $\mathrm{Cu}(\mathrm{II})$. The control conditions of the flocculation process are: $\mathrm{G}$ value $150 \mathrm{~s}^{-1}$, reaction time $2 \mathrm{~h}, \mathrm{pH} 5$, precipitation magnetic field intensity $60 \mathrm{mT}$. The magnetic field strength is measured by a Gauss meter, and the strength of the magnetic field is controlled by adjusting the distance between the magnet block and the beaker. The $\mathrm{Cu}(\mathrm{II})$ removal rate is the percentage of the 
remaining $\mathrm{Cu}(\mathrm{II})$ concentration in the solution after coagulation to the $\mathrm{Cu}(\mathrm{II})$ concentration in the initial solution.

\section{Results and Discussion}

\subsection{MF@AA Characterization}

SEM images of MF, MFM, and MF@AA are given in Figure 1. As shown in Figure 1, the appearance of MF is scattered and granular, with rough and uneven surfaces and undulations. MF has a larger specific surface area after grafting monomer AM, and the surface has a prominent convex structure. At the same time, based on breaking the original $\mathrm{MF}$, the surface becomes rougher, and there is a $2-10 \mu \mathrm{m}$ hole structure. On the other hand, MF@AA has a larger pore structure, and the specific surface area is further increased compared to that of MFM. The obtained SEM data revealed the presence of MF on the surfaces. In addition, the surface of AMPS is chelated and attached to the site, making the surface appear as a more convex structure of the hole.

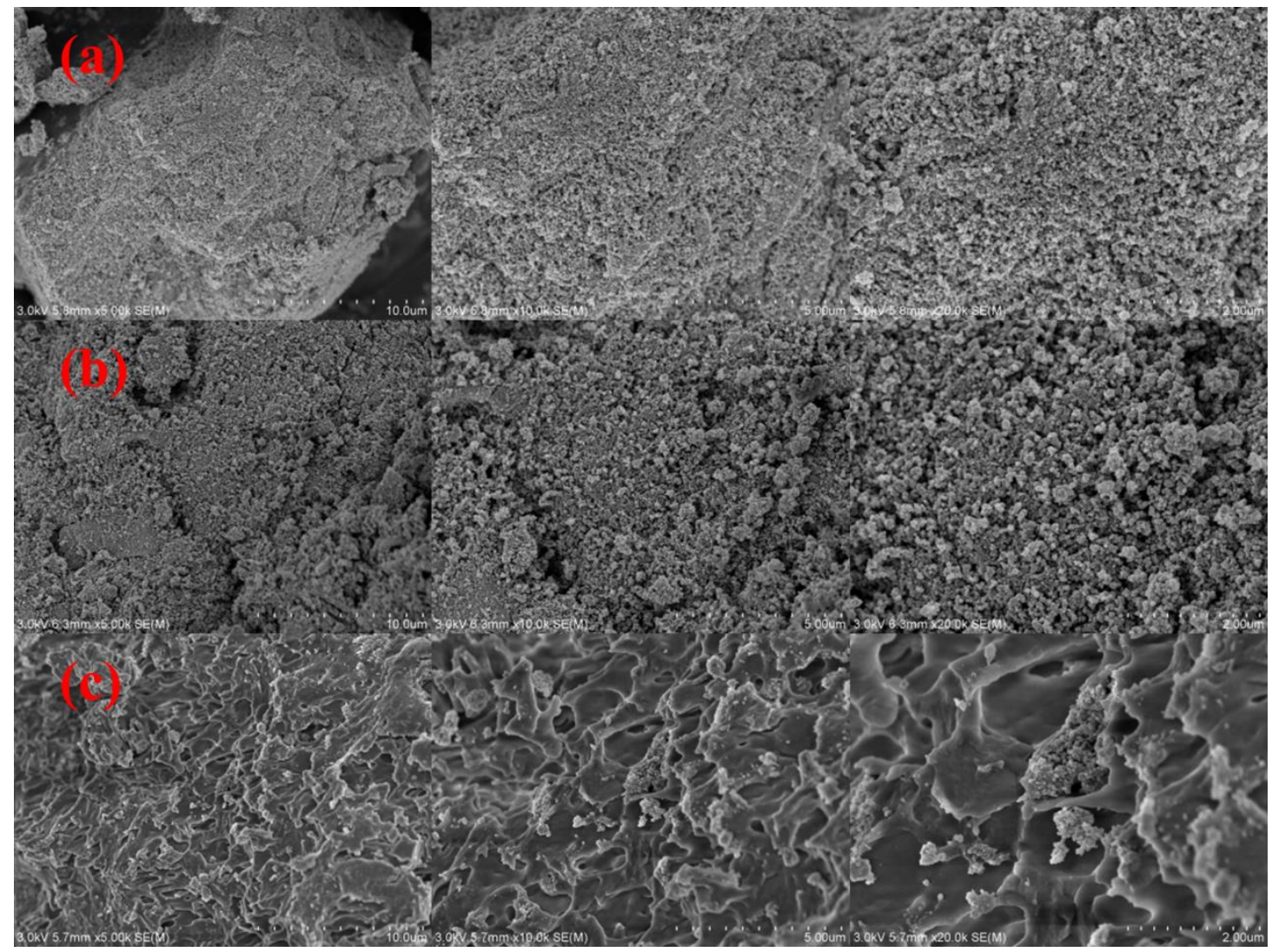

Figure 1. SEM images of magnetic flocculants: (a) MF, (b) MFM, and (c) MF@AA.

Physico-chemical properties and the presence of MF@AA on the modified surfaces can be characterized by FTIR, XRD, XPS and VSM techniques, and the obtained data are presented in Figure 2. FTIR spectra of MF, MFM and MF@AA are shown in Figure 2a. In the MF@AA sample, the peak at $578 \mathrm{~cm}^{-1}$ is attributed to $\mathrm{Fe}-\mathrm{O}$ vibration. Meanwhile, the peak at $1040 \mathrm{~cm}^{-1}$ is attributed to the $-\mathrm{CO}$ stretching vibration peak and the symmetric stretching vibration peak of the sulfonic acid group $\left(-\mathrm{SO}_{3} \mathrm{H}\right)$, which confirms the presence of the modifier on MF@AA. In addition, the symmetrical and asymmetrical stretching vibration peaks of the sulfonic acid group $\left(-\mathrm{SO}_{3} \mathrm{H}\right)$ are located at $1187 \mathrm{~cm}^{-1}$ [18]. The peak at $1040 \mathrm{~cm}^{-1}$ is commonly present in all MF, MFM and MF@AA samples, and it shows that $\mathrm{Fe}_{3} \mathrm{O}_{4}$ and carboxymethyl chitosan form a good and firm $\mathrm{N}-\mathrm{O}$ coordination bond. Comparing MF@AA and MFM, a new characteristic peak appears at $1187 \mathrm{~cm}^{-1}$, where there are the symmetric and asymmetric stretching vibration peaks of the sulfonic acid 
group $\left(-\mathrm{SO}_{3} \mathrm{H}\right)$, indicating that AMPS was successfully grafted [19]. Figure $2 \mathrm{~b}$ presents the XRD pattern of MF, MFM and MF@AA. The XRD pattern of MF has broad diffraction peaks at $2 \theta$ angles of $22^{\circ}$, and sharper diffraction peaks at $2 \theta$ angles of $30^{\circ}, 35^{\circ}, 44^{\circ}, 54^{\circ}$, $57^{\circ}, 63^{\circ}$, and $74^{\circ}$. A new weaker diffraction peak appears in MFM at a $2 \theta$ angle of $70^{\circ}$. The positions of the remaining peaks remain basically unchanged, and the peak intensity is slightly weakened. The XRD pattern of MF@AA has weak diffraction peaks at $2 \theta$ angles of $35^{\circ}, 57^{\circ}$, and $63^{\circ}$ [20]. Comparing the XRD patterns of MF@AA and MF, the intensity of the diffraction peaks of MF@AA at $2 \theta$ angles of $35^{\circ}, 57^{\circ}$, and $63^{\circ}$ is significantly weaker. This is because after AM and AMPS are grafted and polymerized, the sulfonic acid groups on AMPS make hydrogen bonds easier to generate, and the degree of crystal disorder further increases, resulting in a reduction in the hydrogen bond force of $-\mathrm{OH}$ and $-\mathrm{NH}_{2}$ in the chitosan molecule [21].

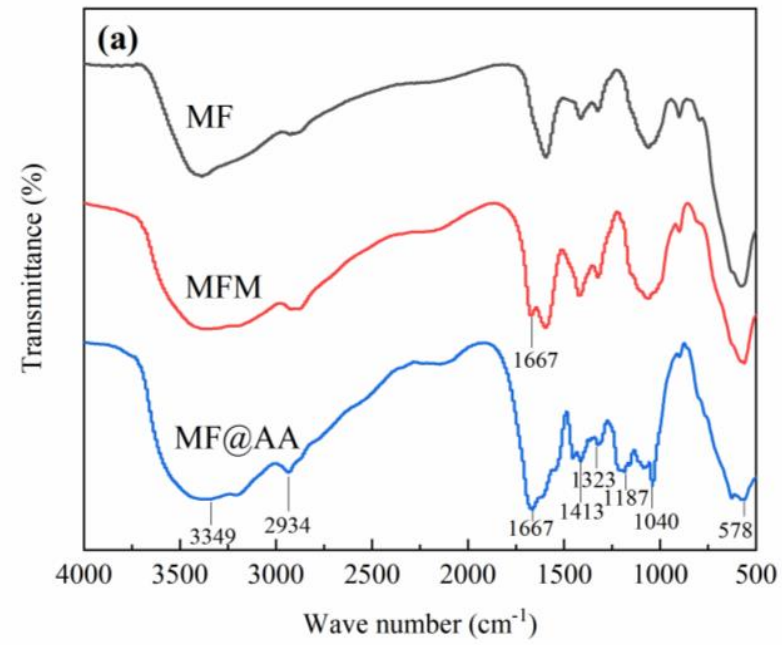

(a)

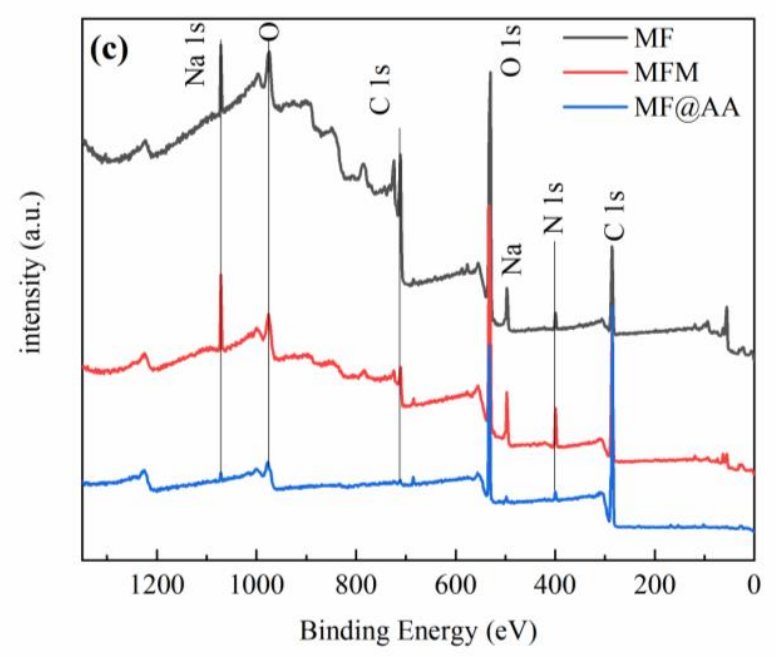

(c)

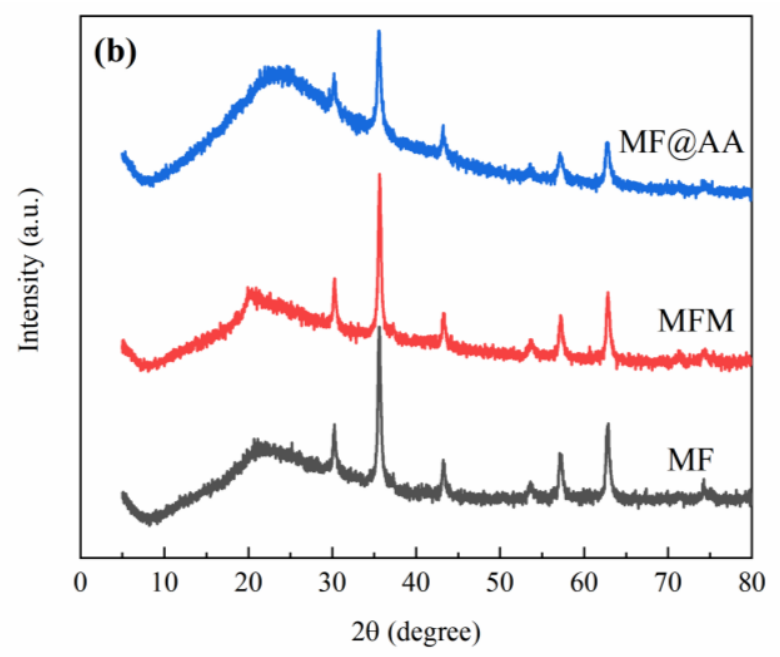

(b)

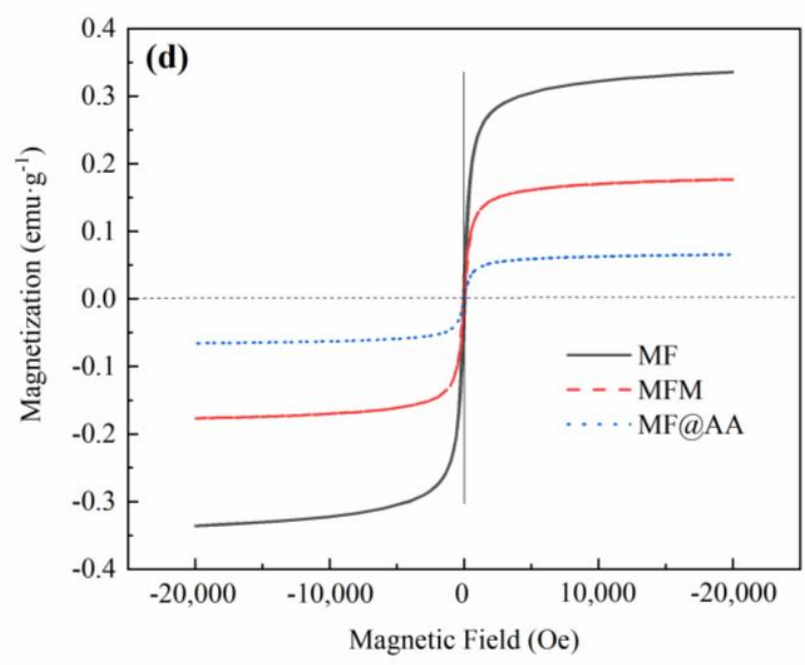

(d)

Figure 2. Characterization of magnetic flocculants: (a) FTIR spectrum, (b) XRD spectrum, (c) XPS images, and (d) VSM curve of magnetic flocculants.

Figure 2c presents the XRD pattern of MF, MFM and MF@AA. As shown in Figure 2c, the characteristic peaks of $S 2 p$ and Fe $2 p$ were found at the binding energy of $168 \mathrm{eV}$ and $711 \mathrm{eV}$, respectively. Comparing the XPS spectra of MF, MFM and MF@AA, it can be seen that the characteristic peak intensity of $C 1 \mathrm{~s}$ has been greatly increased for the case of 
MF@AA, which indicates that the organic monomer has been successfully grafted. On the other hand, the characteristic peaks at Fe 2p are weaker due to the coverage of the organic layer on the surface after the grafting of organic monomers, which reduces the X-ray transmittance [21]. There is an obvious characteristic peak of S 2p on the MF@AA curve, and there is no such peak on the MF and MFM curves. This is due to the grafting of sulfonic acid groups on MF@AA, which also indicates that AMPS has been successfully grafted onto MF [22]. In Figure 2d, the saturation magnetization of the three organic flocculants, MF, MFM and MF@AA, is present. The magnetization of all samples was increased with the increasing magnetic field. The final saturation magnetization (Ms) is found at 0.34 , 0.18, 0.06 (emu/g). MF@AA is grafted with organic monomer AM and AMPS to reduce the $\mathrm{Fe}_{3} \mathrm{O}_{4}$ content per unit mass, and the non-magnetic organic matter is wrapped on the surface of the magnetic particles, which also affects the orientation of the magnetic field on the particles and has a certain weakening effect on the magnetic properties of $\mathrm{Fe}_{3} \mathrm{O}_{4}$ [23]. As a result, the saturation magnetization Ms decreases. Figure 2d shows that MF@AA exhibits superparamagnetism and good magnetic responsiveness.

\subsection{Synthesis Parameters Affecting $\mathrm{Cu}$ Removal Capacity}

\subsubsection{Effect of AMPS Content on MF@AA Flocculation Performance}

The concentration of AMPS is one of the most important variables in adsorption studies as it directly affects the surface charge. It can be seen from Figure 3 that the AMPS content is increasing, and the removal rate of $\mathrm{Cu}$ (II) by MF@AA showed an upward trend till the concentration of AMPS was 10\%. However, the AMPS content exceeded $10 \%$, and the removal rate of $\mathrm{Cu}(\mathrm{II})$ decreased rapidly with the increase in AMPS content. At the same time, the dosage increased from $40 \mathrm{mg} / \mathrm{L}$ to $80 \mathrm{mg} / \mathrm{L}$, and the removal rate of $\mathrm{Cu}(\mathrm{II})$ by MF@AA increased significantly. When the dosage is $80 \mathrm{mg} / \mathrm{L}$ and the CMFS content is $10 \%$, the removal rate of $\mathrm{Cu}$ (II) reaches the maximum value of $77.21 \%$. With the increase in AMPS content, the growing chain between AMPS and AM is continuously added, and the sulfonic acid groups on MF@AA increase, which is beneficial to improve the removal rate of $\mathrm{Cu}(\mathrm{II})$. When the AMPS content increases to a certain level, it will cause agglomeration formation, which significantly reduces the active groups of heavy metals and reduces the water solubility of MF@AA. This agglomeration formation behavior resulted in the nonconductivity of MF@AA towards the removal of $\mathrm{Cu}$ (II) [24]. At the same time, increasing the content of AMPS also means that the $\mathrm{Fe}_{3} \mathrm{O}_{4}$ components were reduced, which causes the magnetic properties of MF@AA to be decreased, the settling time required for the flocs increases, and the removal rate of $\mathrm{Cu}$ (II) decreases [25].

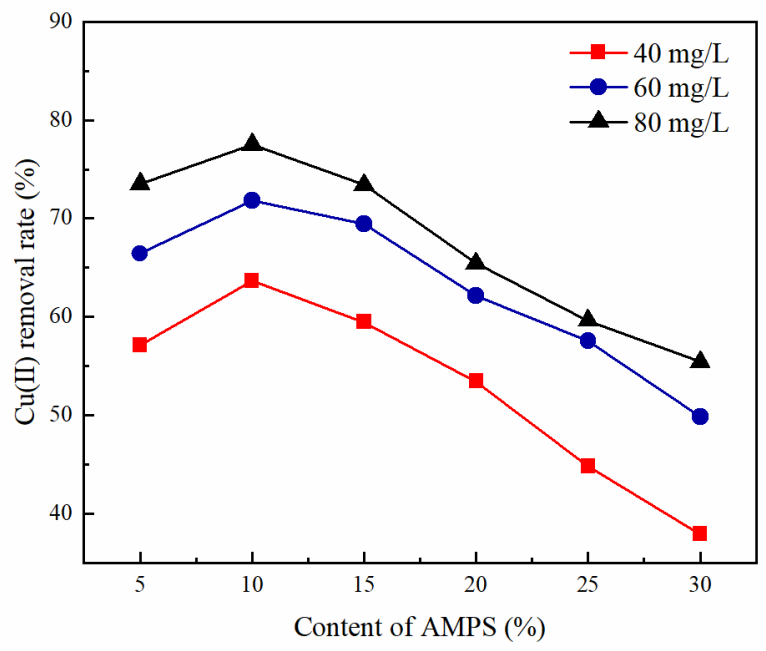

Figure 3. Effect of AMPS content on $\mathrm{Cu}(\mathrm{II})$ removal efficiency. 


\subsubsection{Effect of Total Monomer Concentration on MF@AA Flocculation Performance}

To examine the effect of total monomer concentration on MF@AA flocculation performance on the $\mathrm{Cu}$ (II) removal rate, samples with $15-40 \%$ of total monomer concentration were synthesized, and the obtained results are presented in Figure 4. It can be seen from Figure 4 that when the total monomer concentration was below $35 \%$, the removal rate of $\mathrm{Cu}$ (II) by MF@AA increased with the increase in the total monomer concentration. When the total monomer concentration reached $35 \%$, the removal rate reached the highest value of $79.68 \%$. Meanwhile, the total monomer concentration exceeded $35 \%$, and the removal rate of $\mathrm{Cu}$ (II) by MF@AA decreased with the increase in the total monomer concentration. The yield of MF@AA increased with the increase in the total monomer concentration below $35 \%$. After the total monomer concentration exceeds $35 \%$, the yield has a downward trend with the increase in the total monomer concentration. The maximum yield is $67.29 \%$ at a monomer concentration of $35 \%$.

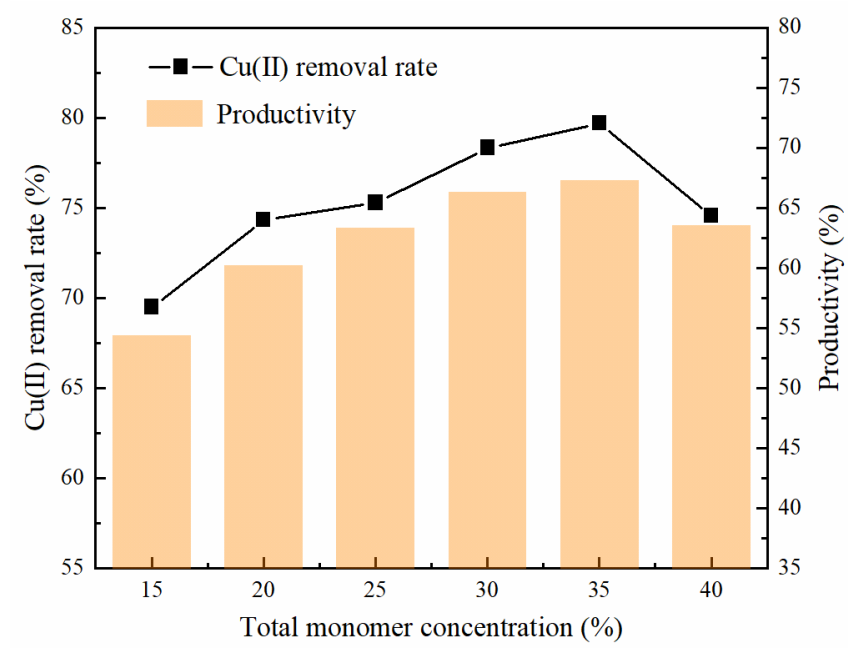

Figure 4. Effect of total monomer concentration on the productivity of MF@AA and Cu(II) removal efficiency.

When the total monomer concentration is low, the probability of contact and collision between the monomers is low, so that the substitution and addition reactions cannot proceed ultimately, and the molecular chain of the generated organic high molecular polymer is short. The generation amount is small [26]. On the other hand, the total monomer concentration increases. The probability of contact and collision between the monomers increases, resulting in a complete reaction by generating a longer molecular chain, and a higher conversion yield can be obtained [27]. However, with the further increase in the total monomer concentration, a too high reactant concentration makes the solution too viscous, which reduces the probability of reaction between monomers, and the yield decreases, and the molecular chain of the product further grows at this time. The $\mathrm{N}$ and $\mathrm{O}$ elements in the long chain of MF@AA make hydrogen bonds between chains and crosslinks occur, reducing the number of effective groups for removing $\mathrm{Cu}$ (II) [28]. At the same time, the excessively long molecular chain also reduces the water solubility of MF@AA, thereby reducing the removal rate of $\mathrm{Cu}(\mathrm{II})$.

\subsubsection{Effect of Photoinitiator Concentration on MF@AA Flocculation Performance}

In addition to AMPS content and total monomer concentration, photoinitiator concentration directly affects the $\mathrm{Cu}(\mathrm{II})$ removal concentration. The photoinitiator can generate free radicals after receiving UV irradiation to initiate the polymerization reaction. As shown in Figure 5, when the photoinitiator concentration is less than $0.04 \%$, the removal rate of $\mathrm{Cu}(\mathrm{II})$ by MF@AA increases rapidly with the increase in the photoinitiator concentration. The results show that the highest $\mathrm{Cu}(\mathrm{II})$ removal rate was obtained, i.e., $85.63 \%$, 
when the photoinitiator concentration was $0.04 \%$. However, the removal rate of $\mathrm{Cu}$ (II) by MF@AA decreases with the increase in the photoinitiator concentration beyond $0.04 \%$. This is because the generation of free radicals rate is slow when the concentration of the photoinitiator is low, the number is small, and the active center of the reaction system is few, which is not conducive to the growth of the molecular chain [29]. The adsorption bridging effect and net sweeping effect of short molecular chain polymer organic products are reduced when flocculating [30]. Therefore, as the concentration of the photoinitiator increases, the removal rate and yield of $\mathrm{Cu}(\mathrm{II})$ increase. When the photoinitiator reaches a certain level, the excessive free radicals generated by the photoinitiator increase the collision between active centers, which increases the probability of molecular chain breakage and termination, which is not conducive to the generation of long chains [31].

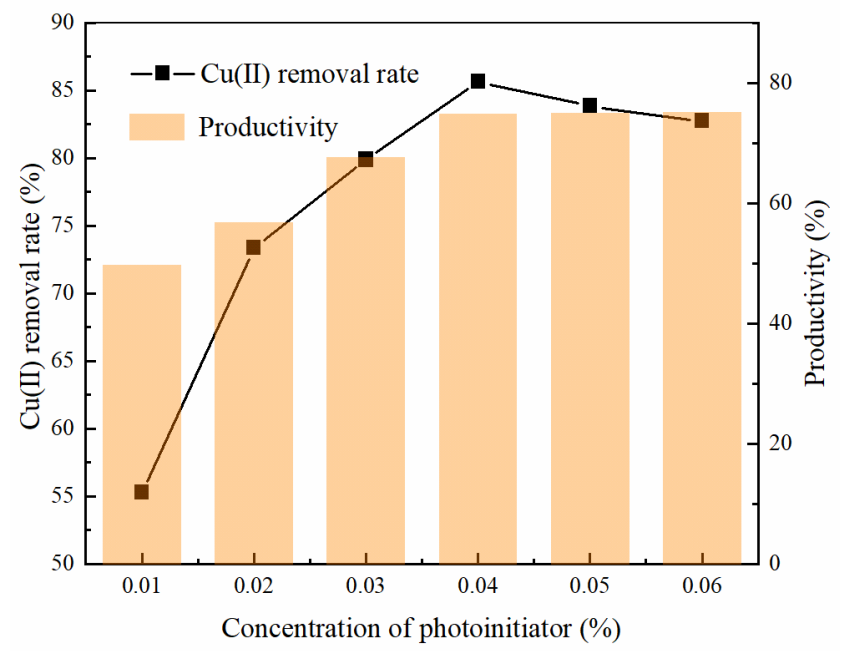

Figure 5. Effect of photoinitiator concentration on the productivity of MF@AA and Cu(II) removal efficiency.

For the case of yield, when the photoinitiator concentration is less than $0.04 \%$, the yield of MF@AA increases with the increase in the photoinitiator concentration and reaches the maximum yield of $74.87 \%$ at $0.04 \%$ and beyond. The yield of MF@AA remained unchanged after increasing $0.04 \%$ of the photoinitiator concentration. In summary, the optimal photoinitiator concentration for the synthesis of MF@AA is $0.04 \%$.

\subsubsection{Effect of Reaction Time on MF@AA Flocculation Performance}

It can be seen from Figure 6 that as the reaction time increases, the removal rate of $\mathrm{Cu}$ (II) by MF@AA also increases. When the reaction time reaches $1.5 \mathrm{~h}$, the removal rate of $\mathrm{Cu}$ (II) remains stable. At this time, the removal rate of $\mathrm{Cu}$ (II) was obtained to be $87.65 \%$. When the reaction time exceeds $1.5 \mathrm{~h}$, the removal rate of $\mathrm{Cu}(\mathrm{II})$ by MF@AA tends to be stable. On the other hand, with the increase in the reaction time, the yield of MF@AA also continued to be increased. When the reaction time was $1.5 \mathrm{~h}$, the yield reached the highest value of $77.69 \%$. After the reaction time exceeded $1.5 \mathrm{~h}$, the yield of MF@AA became steady.

Under the irradiation of ultraviolet light, the activation energy required for the polymerization reaction to occur decreases, the rate of intermolecular bond formation increases, and the substitution and addition reactions between monomers (MF, AM, AMPS) proceed entirely, so there is an increase in reaction time with MF@AA. The removal rate of $\mathrm{Cu}$ (II) increased first and then decreased slowly [32]. However, as the reaction time increases extensively, part of the polymer monomers will undergo cross-linking reactions. At the same time, prolonged irradiation causes the temperature in the reaction system to be too high, which reduces the water content of the mixed liquid, increases the viscosity, and causes the free radicals between monomers and their reactivity to decrease, so the removal rate of $\mathrm{Cu}$ (II) by MF@AA and the yield have a downward trend [33]. After comprehensively 
comparing the optimal conditions of removal rate and yield, the optimal reaction time for the synthesis of MF@AA should be $1.5 \mathrm{~h}$.

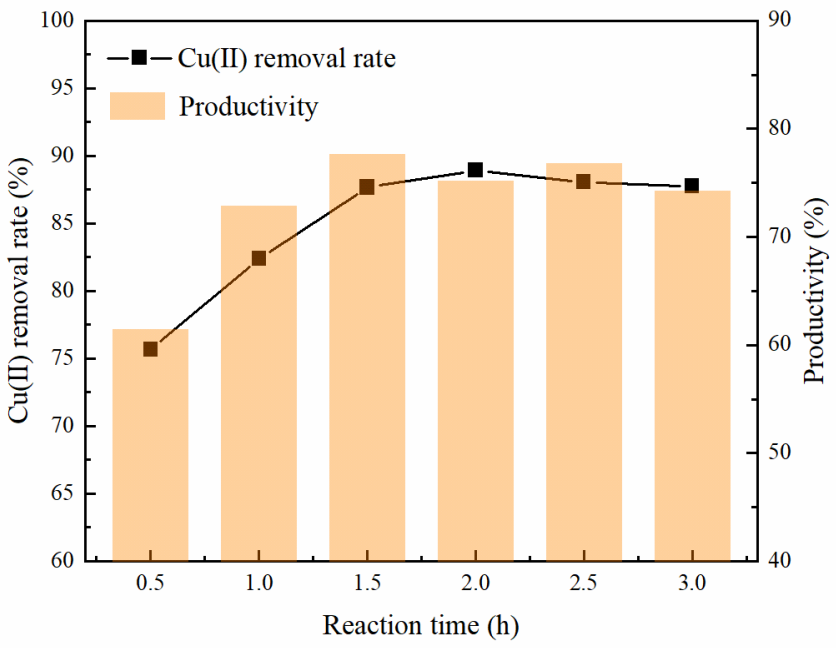

Figure 6. Effect of reaction time on the productivity of MF@AA and $\mathrm{Cu}(\mathrm{II})$ removal efficiency.

\subsection{Response Surface Optimization of MF@AA Synthesis}

\subsubsection{Experimental Design}

In this experiment, Central Composite was selected as the response surface design model. The quality of $\mathrm{FeSO}_{4}$ and $\mathrm{FeCl}_{3}$ (iron composition), CMFS quality, AM quality and AMPS quality were used as independent variables. Based on the optimal ratio determined by the single-factor experiment, the iron component, CMFS, AM, and AMPS fluctuate up and down $1.25 \mathrm{~g}, 2.25 \mathrm{~g}, 2.25 \mathrm{~g}$, and $1.625 \mathrm{~g}$, respectively. We determined the scope of the experiment. The factor levels are shown in Table 1.

Table 1. Component quality level of each factor.

\begin{tabular}{cccc}
\hline Ingredient & Unit & Lower Limit & Upper Limit \\
\hline Iron component & $\mathrm{g}$ & 0.81 & 3.06 \\
CMFS & $\mathrm{g}$ & 2.34 & 6.84 \\
AM & $\mathrm{g}$ & 5.85 & 10.35 \\
AMPS & $\mathrm{g}$ & 0.50 & 3.75 \\
\hline
\end{tabular}

\subsubsection{Response Surface Analysis}

As shown in Figure S2a,b, the slope of the iron component and CMFS's removal rate of $\mathrm{Cu}(\mathrm{II})$ on the response surface graph is relatively large. Therefore, the iron component mass and the CMFS mass affect the removal of $\mathrm{Cu}(\mathrm{II})$ by MF@AA. The performance impact is more prominent. At the same time, the contour line is shown as an ellipse, which shows that the interaction between the iron component and CMFS is more significant. As shown in Figure S2c,d, the slope of AM mass to $\mathrm{Cu}$ (II) removal rate is relatively large on the response surface. In contrast, the slope of iron component mass to $\mathrm{Cu}$ (II) removal rate is small, indicating that AM mass affects MF@AA removal. The effect of Cu(II) on the properties is greater than that of the iron component. At the same time, the contour line is shown as an ellipse, which shows that the interaction between the iron component and AM is more significant. Figure S2e,f show the response surface and contour plots of iron composition and AMPS to the $\mathrm{Cu}$ (II) removal rate. It can be seen from the figure that the slope corresponding to AMPS is relatively large, while the slope corresponding to the iron component is relatively small, indicating that AMPS has a more significant effect on the removal of $\mathrm{Cu}(\mathrm{II})$ by MF@AA than the iron component. At the same time, the contour line is shown as an oblong ellipse, which shows that the interaction between the iron component 
and AMPS is more significant [34]. As shown in Figure S2g,h, the slope of CMFS quality and $\mathrm{AM}$ quality on the $\mathrm{Cu}(\mathrm{II})$ removal rate is relatively large on the response surface, which shows that CMFS and AM have greater performance in removing Cu(II) from MF@AA. At the same time, the contour lines of CMFS and AM concerning the removal rate of $\mathrm{Cu}$ (II) are shown as a prolate ellipse, which shows that the interaction between CMFS and AM is more significant. As shown in Figure S2i,j, the slope of AMPS quality to $\mathrm{Cu}$ (II) removal rate is relatively large on the response surface, while the slope of CMFS quality to $\mathrm{Cu}$ (II) removal rate is small, indicating that AMPS's removal of $\mathrm{Cu}$ (II) from MF@AA has a greater performance impact than CMFS [35]. At the same time, the ellipse formed by the contour lines of CMFS and AMPS is similar to the circle, which shows that the interaction between CMFS and AMPS is relatively insignificant. As shown in Figure S2k,l, the slope of AM and AMPS on the $\mathrm{Cu}(\mathrm{II})$ removal rate is rather large on the response surface, indicating that AM and AMPS have a significant impact on the performance of MF@AA to remove $\mathrm{Cu}$ (II) [36]. At the same time, their contour lines are nearly circular, which shows that the interaction between AM and AMPS is not significant.

\subsubsection{Response Surface Variance Analysis}

$$
\begin{gathered}
\mathrm{Cu}(\mathrm{II}) \text { removal rate }=30.10-1.19 \mathrm{~A}+2.48 \mathrm{~B}+9.95 \mathrm{C}+7.05 \mathrm{D}+0.89 \mathrm{AB}-0.24 \mathrm{AC} \\
+0.76 \mathrm{AD}+0.47 \mathrm{BC}+0.47 \mathrm{BD}-0.14 \mathrm{CD}-1.07 \mathrm{~A}^{2}-0.84 \mathrm{~B}^{2}-0.60 \mathrm{C}^{2}-2.46 \mathrm{D}^{2}
\end{gathered}
$$

The obtained results of response surface experiments are shown in Table S1. The $\mathrm{Cu}$ (II) removal rate obtained in each group of experiments in Table 2 was subjected to multiple regression analysis. The regression of iron composition, CMFS, AM, and AMPS concerning the $\mathrm{Cu}$ (II) removal rate was obtained. Equation (1) shows the calculation used for obtaining the data. As shown in Table 2, the regression term is more significant, and the lack of fit time is not significant. Meanwhile, the model F value is 15.49 , which shows that the selection of the model is more reasonable and the fit degree of the experiment is higher. Through the $p$-value, we can see the significance and the interactive relationship of each experimental variable. The $p$-value is within the range of 0.0001 to 0.05 . It can be seen that the iron composition, CMFS, and AM are the difference between MF@AA and $\mathrm{Cu}(\mathrm{II})$ in this range. Obtained data are a significant factor in the removal rate, and their influence on the removal rate of $\mathrm{Cu}(\mathrm{II})$ is in the order of $\mathrm{AM}>\mathrm{CMFS}>$ iron component. The interactions of iron component (A) and CMFS (B), iron component (A) and AM (C), CMFS (B) and AM (C) are apparent, and they are in the order of $\mathrm{BC}$ interaction $>\mathrm{AB}$ interaction $>\mathrm{AC}$ interaction. In addition, the multiple correlation coefficient $\left(R^{2}\right)$ of the model is 0.9353 . The correction determination coefficient of the model is 0.8749 , and the coefficient of variation CV is $6.36 \%$, indicating that the model can explain $87.49 \%$ of the response value change. It has a high degree of matching with the actual experiment. Solving Equation (1) shows that the optimal conditions are $1.27 \mathrm{~g}$ for iron content, $5.40 \mathrm{~g}$ for CMFS, $9.86 \mathrm{~g}$ for AM, and $1.81 \mathrm{~g}$ for AMPS, corresponding to $6.5 \%$ for iron content, $29.5 \%$ for CMFS, and 53.9\% for AM, AMPS: $10.1 \%$, respectively. At this time, the forecast can reach $91.67 \%$. Experiments tested the optimized finished product. The three tests' $\mathrm{Cu}$ (II) removal rates were $88.67 \%, 90.32 \%$, and $89.03 \%$, respectively. The relative error between the average value and the predicted value was $2.33 \%$, indicating that the response surface experiment has high credibility. The presence of copper in water is related to the $\mathrm{pH}$ value. Under neutral and alkaline conditions, $\mathrm{Cu}$ (II) ions in the solution can gradually form hydroxide colloids and precipitates. $\mathrm{Cu}$ (II) may also generate positively charged colloids such as $\mathrm{Cu}(\mathrm{OH})^{+}$. The colloids and precipitates of $\mathrm{Cu}$ (II) produced due to $\mathrm{pH}$ changes are removed by MF@AA through flocculation. Some $\mathrm{Cu}$ (II) ions are removed by chelating with anionic groups on MF@AA to produce chelates. Therefore, MF@AA achieves the removal of $\mathrm{Cu}$ (II) ions through the combined effects of flocculation, chelation, and adsorption. The removal of $\mathrm{Cu}$ (II) mainly relies on the electrostatic attraction and coordination chelation between $-\mathrm{NH}_{2},-\mathrm{OH},-\mathrm{COOH}$ and $\mathrm{Cu}$ (II) in the magnetic flocculant. Carboxylate anions exist in the form of strong electrostatic attraction with $\mathrm{Cu}(\mathrm{II})$. $-\mathrm{NH}_{2}$ has strong coordination and chelation to $\mathrm{Cu}(\mathrm{II})$. Under low $\mathrm{pH}$ 
conditions, the concentration of $\mathrm{H}^{+}$in the solution is high, and $-\mathrm{NH}_{2}$ will be protonated to form $-\mathrm{NH}_{3}{ }^{+}$, resulting in a smaller number of $-\mathrm{NH}_{2}$ that can effectively complex $\mathrm{Cu}$ (II) in the magnetic flocculant. At the same time, the existence of a large amount of $\mathrm{H}^{+}$will form an electrostatic repulsion with $\mathrm{Cu}(\mathrm{II})$, preventing effective contact between $\mathrm{Cu}(\mathrm{II})$ and the flocculant, resulting in a low removal rate of $\mathrm{Cu}(\mathrm{II})$.

Table 2. Variance analysis of response surface model.

\begin{tabular}{cccccc}
\hline & Sum of & & Mean & F & $p$-Value \\
\hline Source & Squares & Df & Square & Value & Prob > F \\
\hline Model & 2350.05 & 14 & 167.8607 & 15.49098 & $<0.0001$ \\
A-Fe component & 59.08852 & 1 & 59.08852 & 5.452967 & 0.0338 \\
B-CMFS & 192.157 & 1 & 192.157 & 17.73316 & 0.0008 \\
C-AM & 293.3703 & 1 & 293.3703 & 27.0736 & 0.0001 \\
D-AMPS & 44.89633 & 1 & 44.89633 & 4.143245 & 0.0599 \\
AB & 81.94776 & 1 & 81.94776 & 7.562526 & 0.0149 \\
AC & 5.700156 & 1 & 5.700156 & 0.526037 & 0.4794 \\
AD & 30.55326 & 1 & 30.55326 & 2.819599 & 0.1138 \\
BC & 90.01266 & 1 & 90.01266 & 8.306793 & 0.0114 \\
BD & 47.09391 & 1 & 47.09391 & 4.346048 & 0.0546 \\
CD & 4.192256 & 1 & 4.192256 & 0.386881 & 0.5433 \\
A^2 & 32.2143 & 1 & 32.2143 & 2.972887 & 0.1052 \\
B^2 & 515.1256 & 1 & 515.1256 & 47.53822 & $<0.0001$ \\
C^2 & 264.2703 & 1 & 264.2703 & 24.38811 & 0.0002 \\
D^2 & 749.7637 & 1 & 749.7637 & 69.19173 & $<0.0001$ \\
Residual & 162.5405 & 15 & 10.83603 & &
\end{tabular}

\section{Conclusions}

In this study, magnetic CMFS, AM, and AMPS were used as reactive monomers. A high-efficiency magnetic flocculant MF@AA was prepared by photo-polymerization technology and used for the flocculation process to remove $\mathrm{Cu}(\mathrm{II})$. The FTIR and XRD patterns showed that new characteristic peaks appeared in the polymer, which confirmed the successful introduction of new elements and groups. The VSM spectrum shows that the prepared magnetic polymer flocculant is super-paramagnetic. SEM images show that after grafting organic monomers, MF@AA appears to have many disordered pore structures, which helps to improve water solubility. Under the optimal flocculation conditions, the maximum removal rate of $\mathrm{Cu}$ (II) in simulated heavy metal wastewater by MF@AA was $87.65 \%$. After flocculation, the content of $\mathrm{Cu}$ (II) reached the national emission standard, indicating that MF@AA has good potential in the treatment of heavy metal wastewater. In addition, the Central Composite model was used to optimize the synthesis content ratio of MF@AA. The best synthesis ratio was obtained as follows: iron content $6.5 \%$, CMFS: $29.5 \%$, AM: $53.9 \%$, AMPS: $10.1 \%$. The removal rate of $\mathrm{Cu}(\mathrm{II})$ can reach $91.67 \%$, and the relative error between the average value of the verified experiment and the predicted value of the model is $2.33 \%$. The prepared magnetic flocculant MF@AA has excellent chelating flocculation performance and good magnetic characteristics and is expected to show good application prospects in removing soluble heavy metal ions in wastewater.

Supplementary Materials: The following are available online at https:/ /www.mdpi.com/article/ 10.3390/w13131732/s1, Figure S1: Preparation scheme of MF@AA, Figure S2: Response surface and contour map of: (a,b) Fe and CMFS, (c,d) Fe and AM, (e,f) Fe and AMPS, (g,h) CMFS and AM, $(\mathbf{i}, \mathbf{j})$ CMFS and AMPS, and $(\mathbf{k}, \mathbf{l})$ AM and AMPS on the removal efficiency of $\mathrm{Cu}(\mathrm{II})$ by MF@AA, Table S1: Design and results of response surface experiments.

Author Contributions: Conceptualization, J.Z. and Y.Y.; methodology, J.Z.; software, Y.S.; validation, J.Z., Y.S. and A.C.; formal analysis, J.Z.; investigation, A.C.; data curation, J.Z. and Y.S.; writing- 
original draft preparation, J.Z.; writing-review and editing, Y.S., Y.Y., A.C. and K.J.S.; supervision, Y.S. and K.J.S.; project administration, Y.S.; funding acquisition, Y.S. All authors have read and agreed to the published version of the manuscript.

Funding: This research was supported by the National Natural Science Foundation of China (No. 51508268), Natural Science Foundation of Jiangsu Province in China (No. BK20201362), and 2018 Six Talent Peaks Project of Jiangsu Province (JNHB-038).

Institutional Review Board Statement: Not applicable.

Informed Consent Statement: Not applicable.

Data Availability Statement: The data presented in this study are available on request from the corresponding author.

Conflicts of Interest: The authors declare no conflict of interest.

\section{References}

1. Kang, J.; Kim, T.; Park, J.W.; Lee, K.; Park, D.H.; Park, S.; Kim, S.; Jung, Y. A Mesoporous Chelating Polymer-Carbon Composite for the Hyper-Efficient Separation of Heavy Metal Ions. J. Nanosci. Nanotechnol. 2020, 20, 3042-3046. [CrossRef]

2. Jia, T.; Xu, K.; Wu, J.; Liu, Q.; Lin, Y.; Gu, M.; Tian, F.; Pan, W.; Wu, J.; Xiao, Y. Constructing 2D BiOIO3/MoS2 Z-scheme heterojunction wrapped by $\mathrm{C} 500$ as charge carriers transfer channel: Enhanced photocatalytic activity on gas-phase heavy metal oxidation. J. Colloid Interf. Sci. 2020, 562, 429-443. [CrossRef] [PubMed]

3. Yang, Y.; Li, J.; Yan, T.; Zhu, R.; Yan, L.; Pei, Z. Adsorption and photocatalytic reduction of aqueous $\mathrm{Cr}(\mathrm{VI})$ by $\mathrm{Fe}_{3} \mathrm{O}_{4}-\mathrm{ZnAl}-\mathrm{layered}$ double hydroxide/ $\mathrm{TiO}_{2}$ composites. J. Colloid Interf. Sci. 2020, 562, 493-501. [CrossRef] [PubMed]

4. Xiong, W.; Yin, C.; Wang, Y.; Lin, S.; Deng, Z.; Liang, R. Characterization of an efficient estrogen-degrading bacterium Stenotrophomonas maltophilia SJTH1 in saline-, alkaline-, heavy metal-contained environments or solid soil and identification of four 17beta-estradiol-oxidizing dehydrogenases. J. Hazard. Mater. 2020, 385, 121616. [CrossRef]

5. Mao, Y.; Wu, H.; Wang, W.; Jia, M.; Che, X. Pretreatment of municipal solid waste incineration fly ash and preparation of solid waste source sulphoaluminate cementitious material. J. Hazard. Mater. 2020, 385, 121580. [CrossRef]

6. Shafiq, M.; Alazba, A.A.; Amin, M.T. Removal of Heavy Metals from Wastewater using Date Palm as a Biosorbent: A Comparative Review. Sains Malays. 2018, 47,35-49.

7. Wei, H.; Gao, B.Q.; Ren, J.; Li, A.M.; Yang, H. Coagulation/flocculation in dewatering of sludge: A review. Water Res. 2018, 143, 608-631. [CrossRef]

8. Tang, X.M.; Jiang, X.; Zhang, S.X.; Zheng, H.L.; Tan, X.M. Recent Progress on Graft Polymerization of Natural Polymer Flocculants: Synthesis Method, Mechanism and Characteristic. Mini-Rev. Org. Chem. 2018, 15, 227-235. [CrossRef]

9. Salehizadeh, H.; Yan, N.; Farnood, R. Recent advances in polysaccharide bio-based flocculants. Biotechnol. Adv. 2018, 36, 92-119. [CrossRef] [PubMed]

10. Li, X.; Yang, B.; Feng, L.; Zheng, H.; Zeng, G.; Wu, P. Research Progress of Natural Polymers in Wastewater Treatment. Mini-Rev. Org. Chem. 2019, 16, 335-344. [CrossRef]

11. Desbrières, J.; Guibal, E. Chitosan for wastewater treatment. Polym. Int. 2018, 67, 7-14. [CrossRef]

12. Teh, C.Y.; Budiman, P.M.; Shak, K.; Wu, T.Y. Recent Advancement of Coagulation-Flocculation and Its Application in Wastewater Treatment. Ind. Eng. Chem. Res. 2016, 55, 4363-4389. [CrossRef]

13. Lee, C.S.; Robinson, J.; Chong, M.F. A review on application of flocculants in wastewater treatment. Process Saf. Environ. 2014, 92, 489-508. [CrossRef]

14. Sun, W.; Zhou, S.; Sun, Y.; Xu, Y. Synthesis and evaluation of cationic flocculant P(DAC-PAPTAC-AM) for flocculation of coal chemical wastewater. J. Environ. Sci. 2021, 99, 239-248. [CrossRef] [PubMed]

15. Xiao, X.; Yu, Y.; Sun, Y.; Zheng, X.; Chen, A. Heavy metal removal from aqueous solutions by chitosan-based magnetic composite flocculants. J. Environ. Sci. 2021, 108, 22-32. [CrossRef]

16. Sun, Y.; Yu, Y.; Zheng, X.; Chen, A.; Zheng, H. Magnetic flocculation of $\mathrm{Cu}(\mathrm{II})$ wastewater by chitosan-based magnetic composite flocculants with recyclable properties. Carbohyd. Polym. 2021, 261, 117891. [CrossRef]

17. Xiao, X.; Sun, Y.; Liu, J.; Zheng, H. Flocculation of heavy metal by functionalized starch-based bioflocculants: Characterization and process evaluation. Sep. Purif. Technol. 2021, 267, 118628. [CrossRef]

18. Sun, Y.; Zhou, S.; Pan, S.; Zhu, S.; Yu, Y.; Zheng, H. Performance evaluation and optimization of flocculation process for removing heavy metal. Chem. Eng. J. 2020, 385, 123911. [CrossRef]

19. Sun, Y.; Zhou, S.; Sun, W.; Zhu, S.; Zheng, H. Flocculation activity and evaluation of chitosan-based flocculant CMCTS-g-P(AMCA) for heavy metal removal. Sep. Purif. Technol. 2020, 241, 116737. [CrossRef]

20. Wu, P.; Yi, J.; Feng, L.; Li, X.; Chen, Y.; Liu, Z.; Tian, S.; Li, S.; Khan, S.; Sun, Y. Microwave assisted preparation and characterization of a chitosan based flocculant for the application and evaluation of sludge flocculation and dewatering. Int. J. Biol. Macromol. 2020, 155, 708-720. [CrossRef] 
21. Sun, Y.; Sun, W.; Shah, K.J.; Chiang, P.; Zheng, H. Characterization and flocculation evaluation of a novel carboxylated chitosan modified flocculant by UV initiated polymerization. Carbohyd. Polym. 2019, 208, 213-220. [CrossRef] [PubMed]

22. Tang, X.; Huang, T.; Zhang, S.; Zheng, J.; Zheng, H. Synthesis of an amphoteric chitosan-based flocculant and its flocculation performance in the treatment of dissolved organic matter from drinking water. Desalin. Water Treat. 2020, 174, 171-177. [CrossRef]

23. Sun, Y.; Shah, K.J.; Sun, W.; Zheng, H. Performance evaluation of chitosan-based flocculants with good pH resistance and high heavy metals removal capacity. Sep. Purif. Technol. 2019, 215, 208-216. [CrossRef]

24. Chen, F.; Yu, C.; Wei, L.; Fan, Q.; Ma, F.; Zeng, J.; Yi, J.; Yang, K.; Ji, H. Fabrication and characterization of $\mathrm{ZnTiO}_{3} / \mathrm{Zn}_{2} \mathrm{Ti}_{3} \mathrm{O}_{8} / \mathrm{ZnO}$ ternary photocatalyst for synergetic removal of aqueous organic pollutants and Cr(VI) ions. Sci. Total Environ. 2020, 706, 136026. [CrossRef] [PubMed]

25. Bornillo, K.A.S.; Kim, S.; Choi, H. Cu (II) removal using electrospun dual-responsive polyethersulfone-poly (dimethyl amino) ethyl methacrylate (PES-PDMAEMA) blend nanofibers. Chemosphere 2020, 242, 125287. [CrossRef]

26. Louati, I.; Elloumi-Mseddi, J.; Cheikhrouhou, W.; Hadrich, B.; Nasri, M.; Aifa, S.; Woodward, S.; Mechichi, T. Simultaneous cleanup of Reactive Black 5 and cadmium by a desert soil bacterium. Ecotox. Environ. Saf. 2020, 190, 110103. [CrossRef]

27. Tsedenbal, B.; Hussain, I.; Lee, J.E.; Koo, B.H. Removal of Lead Contaminants with gamma-Fe ${ }_{2} \mathrm{O}_{3}$ Nanocrystals. Sci. Adv. Mater. 2020, 12, 422-426. [CrossRef]

28. Li, Y.; Ma, J.; Yuan, Y. Enhanced Adsorption of Chromium by Stabilized Ca/Al-Fe Layered Double Hydroxide Decorated with Ferric Nanoparticles. Sci. Adv. Mater. 2020, 12, 441-448. [CrossRef]

29. Zheng, H.; Sun, Y.; Zhu, C.; Guo, J.; Zhao, C.; Liao, Y.; Guan, Q. UV-initiated polymerization of hydrophobically associating cationic flocculants: Synthesis, characterization, and dewatering properties. Chem. Eng. J. 2013, 234, 318-326. [CrossRef]

30. Zheng, H.; Sun, Y.; Guo, J.; Li, F.; Fan, W.; Liao, Y.; Guan, Q. Characterization and Evaluation of Dewatering Properties of PADB, a Highly Efficient Cationic Flocculant. Ind. Eng. Chem. Res. 2014, 53, 2572-2582. [CrossRef]

31. Sun, Y.; Ren, M.; Zhu, C.; Xu, Y.; Zheng, H.; Xiao, X.; Wu, H.; Xia, T.; You, Z. UV-Initiated Graft Copolymerization of Cationic Chitosan-Based Flocculants for Treatment of Zinc Phosphate-Contaminated Wastewater. Ind. Eng. Chem. Res. 2016, 55, 10025-10035. [CrossRef]

32. Sun, Y.; Zhu, C.; Zheng, H.; Sun, W.; Xu, Y.; Xiao, X.; You, Z.; Liu, C. Characterization and coagulation behavior of polymeric aluminum ferric silicate for high-concentration oily wastewater treatment. Chem. Eng. Res. Des. 2017, 119, 23-32. [CrossRef]

33. Sun, Y.; Zhu, C.; Sun, W.; Xu, Y.; Xiao, X.; Zheng, H.; Wu, H.; Liu, C. Plasma-initiated polymerization of chitosan-based CS-gP(AM-DMDAAC) flocculant for the enhanced flocculation of low-algal-turbidity water. Carbohyd. Polym. 2017, 164, $222-232$. [CrossRef] [PubMed]

34. Zhu, J.R.; Zheng, H.L.; Jiang, Z.Z.; Zhang, Z.; Liu, L.W.; Sun, Y.J.; Tshukudu, T. Synthesis and characterization of a dewatering reagent: Cationic polyacrylamide (P(AM-DMC-DAC)) for activated sludge dewatering treatment. Desalin. Water Treat. 2013, 51, 2791-2801. [CrossRef]

35. Zhu, G.; Zheng, H.; Zhang, Z.; Tshukudu, T.; Zhang, P.; Xiang, X. Characterization and coagulation-flocculation behavior of polymeric aluminum ferric sulfate (PAFS). Chem. Eng. J. 2011, 178, 50-59. [CrossRef]

36. Zhu, G.; Zheng, H.; Chen, W.; Fan, W.; Zhang, P.; Tshukudu, T. Preparation of a composite coagulant: Polymeric aluminum ferric sulfate (PAFS) for wastewater treatment. Desalination 2012, 285, 315-323. [CrossRef] 